\title{
内蒙古锡林郭勒杂岩 $\mathrm{Sm}-\mathrm{Nd}, \mathrm{Rb}-\mathrm{Sr}$ 同位素年代研究 ${ }^{*}$
}

徐 备 陈 斌 郡济安

(北京大学地质学系, 北京 100871)

\section{关键词 锡林郭勒杂岩 $\mathrm{Sm}-\mathrm{Nd}$ 同位事 $\mathrm{Rb}-\mathrm{Sr}$ 同位素 内蒙}

内蒙古锡林浩特市东北约 $100 \mathrm{~km}$ 的巴音高勒地区分布着一套变质岩, 前人曾命名为锡林郭 勒杂岩. 这套岩系具复杂变形和角闪岩相变质, 长期以来时代归属不明且缺乏详细工作. 邵济安 ${ }^{[1]}$ 认为其属古生代褶皱带内的古地体, 唐克东等 ${ }^{[2]}$ 则将其划归古生代花岗 - 变质岩带的 一部分. 在《内蒙古自治区区域地质志》中, 这套岩系被归人早元古代, 但同时报道其 U-Pb 年龄 为 $1060 \mathrm{Ma}^{[3]}$. 由于锡林郭勒杂岩是华北板块北缘古生代褶䏢带内出露面积最大的变形变质 地层单位, 故查明其形成年龄、变质年龄对于解释华北板块北缘前古生代构造演化具有重要 意义.

\section{1 地质概况}

巴音高勒地区的锡林郭勒杂岩出露面积约 $500 \mathrm{~km}^{2}$ (图 1), 地层连续, 由浅灰色二云母片

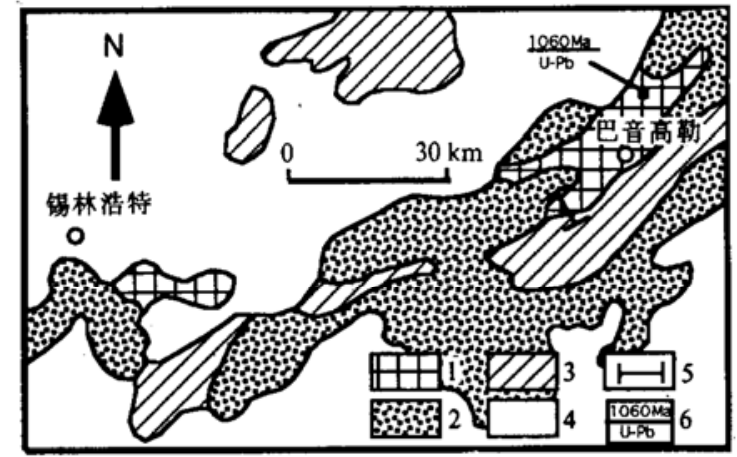

图 1 巴音高勒地区地质略图

1 - 锂林郭勒杂岩, 2 - 花岗岩, 3-上古生界, 4-中 - 新

生界, 5 一一采样剖面位置, 6 一前人所做同位素年龄值 ${ }^{3]}$ 麻岩、黑云母片麻岩夹多层灰绿色角闪斜 长片麻岩、角闪石岩和斜长角闪岩组成. 二 云母片麻岩局部仍残留着小型递变层理 或波痕层理等原生沉积构造. 角闪斜长 片麻岩一般出露宽度十米至数十米, 延伸 稳定且平行区域性片麻理方向, 角闪石岩 和斜长角闪岩出露宽度为 $0.5 \sim 5 \mathrm{~m}$, 多在 角闪斜长片麻岩中以似层状产出. 野外 和镜下特征说明, 各类岩石具有相同的变 质变形特征, 互层关系稳定, 是一套连续 的岩层, 原岩应为滨浅海碎屑沉积夹基 性、中基性火山岩建造. 因此对其中由火 山岩变质形成的角闪石岩、斜长角闪岩和角闪斜长片麻岩进行年代学研究, 可以查明锡林郭 勒杂岩的形成和变质年代.

1995-04-24 收稿, 1995-07-25 收修改稿

*香港霍英东教育基金会和国家教委优秀年轻教师基金资助项目 


\section{2 实验方法与结果}

沿剖面采集样品 20 余块, 经切片镜下观察后挑选 5 块同时用于 $\mathrm{Sm}-\mathrm{Nd}$ 和 $\mathrm{Rb}-\mathrm{Sr}$ 同位素 全岩分析. 所选样品分别为角闪石岩 (BG4, BG5, BG21)、斜长角闪岩 (BG17) 和角闪斜长片 麻岩 (BG14). 样品的化学分离和质谱测定均在中国科学院地质研究所完成, 所用质谱仪为 VG354 型. $\mathrm{Nd}$ 同位素比值测定以 ${ }^{148} \mathrm{Nd} /{ }^{144} \mathrm{Nd}=0.7219$ 为标准化值, 对 $\mathrm{BCR}-1$ 标样 ${ }^{143} \mathrm{Nd} /{ }^{144} \mathrm{Nd}$ 的测定值为 $0.512637 \pm 4(2 \sigma)$, 实验全流程 $\mathrm{Sm}$ 和 $\mathrm{Nd}$ 的空白本底均为 $0.1 \mathrm{ng}$. 对 $\mathrm{Sr}$ 同位素标 样 NBS987 测定的 ${ }^{87} \mathrm{Sr} /{ }^{86} \mathrm{Sr}$ 值是 $0.710220 \pm 10(2 \sigma)$, 实验全流程 $\mathrm{Sr}, \mathrm{Rb}$ 的本底分别是 $0.2 \mathrm{ng}$ 和 $0.3 \mathrm{ng}$. 等时线年龄计算采用 York(1966) 的方法. 详细测试过程及参数可参见文献[4].

测定数据见表 1, 等时线见图 2. Sm-Nd 全岩测试样品为 4 个, 所构成的等时线年龄值是 $1025 \pm 41 \mathrm{Ma}, \varepsilon_{\mathrm{Nd}(T)}$ 为 $6.25 \pm 0.73$. Rb-Sr 全岩测试样品除以上 4 个外, 增加了样品 $\mathrm{BG} 5$, 等时线年龄为 $651.0 \pm 21.3 \mathrm{Ma}$.

表 1 锡林郭勒杂岩 $\mathrm{Sm}-\mathrm{Nd}$ 和 $\mathrm{Rb}-\mathrm{Sr}$ 同位素分析结果

\begin{tabular}{|c|c|c|c|c|c|c|}
\hline 样品号 & $\mathrm{Sm} / 10^{-6}$ & $\mathrm{Nd} / 10^{-6}$ & ${ }^{147} \mathrm{Sm} /{ }^{144} \mathrm{Nd}$ & ${ }^{143} \mathrm{Nd} /{ }^{144} \mathrm{Nd}(2 \sigma)$ & $T(\mathrm{DM})$ & $\varepsilon_{\mathrm{Nk}(n}$ \\
\hline BG4 & 3.351 & 11.496 & 0.1763 & $0.512828 \pm 10$ & 1316 & 6.40 \\
\hline BG14 & 2.521 & 14.402 & 0.1059 & $0.512350 \pm 7$ & 1132 & 6.32 \\
\hline BG17 & 3.844 & 16.682 & 0.1394 & $0.512576 \pm 9$ & 1179 & 6.33 \\
\hline BG21 & 3.811 & 15.286 & 0.1508 & $0.512642 \pm 9$ & 1233 & 6.12 \\
\hline 样品号 & $\mathrm{Rb} / 10^{-6}$ & $\mathrm{Sr} / 10^{-6}$ & & & $(2 \sigma)$ & ${ }^{\ell} \operatorname{Sr}(T)$ \\
\hline BG4 & 60.25 & 166.6 & & & $8 \pm 27$ & -44.7 \\
\hline BGl4 & 123.39 & 217.9 & & & $6 \pm 14$ & -41.5 \\
\hline BG17 & 75.18 & 179.9 & & & $6 \pm 23$ & -47.2 \\
\hline BG21 & 75.68 & 257.3 & & & $2 \pm 21$ & -39.9 \\
\hline BG5 & 55.91 & 204.9 & & & \pm 41 & -40.2 \\
\hline
\end{tabular}

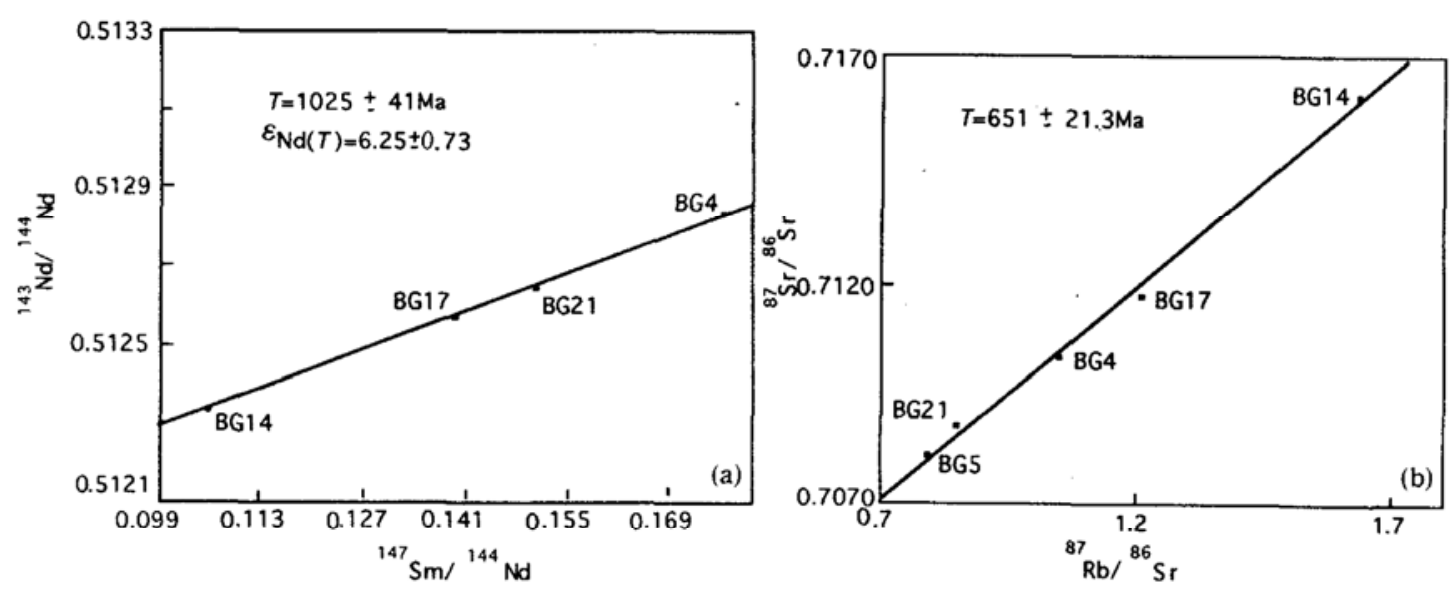

图 $2 \mathrm{Sm}-\mathrm{Nd}(\mathrm{a})$ 和 Rb-Sr(b) 全岩同位素等时线

\section{3 地质解释与构造意义讨论}

$\mathrm{Sm}-\mathrm{Nd}$ 全岩等时线的 4 个点相关性很好, $M S W D=0.2625$, 各样品的 $\varepsilon_{\mathrm{Nd}(I)}$ 值变化于 6.1 
到 6.4 之间,显然为同源岩浆作用产物, 符合等时线成立的条件. 因此等时线年龄 $1025 \mathrm{Ma}$ 可做为锡林郭勒杂岩中火山岩的成岩年代. 前已述及野外观察的互层特征说明火山活动与沉 积作用是连续交替进行的, 故这一数值也应相当于锡林郭勒杂岩的形成年龄, 它表明该岩系 于中元古代末期形成. 该年龄与前人报道的 $1060 \mathrm{Ma}$ 的 U-Pb 法年龄相一致, 这就从 U-Pb 和 Sm-Nd 两种不同的体系印证了锡林郭勒杂岩的同位素地球化学演化特征, 也说明所取得的 年龄值是可信的. 各样品的模式年龄为 $1317 \sim 1132 \mathrm{Ma}$, 平均 $1225 \mathrm{Ma}$, 代表了岩浆从地幔 源区分出的时间.

等时线的 $\varepsilon_{\mathrm{Nd}(T)}$ 值为 $6.25 \pm 0.73$, 表明岩浆来源于中等亏损的地幔源区. 一般认为这类 源区的构造背景属岛弧或边缘海区, 但锡林郭勒杂岩以二云母、黑云母片麻岩为主, 并有残留 的滨浅海沉积构造, 表明其形成于滨浅海碎屑沉积陆缘, 而其中以夹层出现的基性和中基性 火山活动可能说明这种陆缘属于火山型被动陆缘.

$\mathrm{Rb}-\mathrm{Sr}$ 全岩等时线由 5 个点组成, 等时线年龄 $651 \pm 21 \mathrm{Ma}$. 由于 $\mathrm{Rb}-\mathrm{Sr}$ 体系在变质事件 中的开放性, 有理由认为该等时线反映了锡林郭勒杂岩的主期变形变质年代. 该变质年代数 据对于解释华北板块北缘构造演化的重要意义在于: 以锡林郭勒杂岩为代表的区域性中 - 浅 变质和强烈变形显然是一次重要构造运动的结果, 标志着华北板块北缘结束元古代陆缘发育 进人古生代发展, 但长期以来末得到这次构造运动的年代学证据. 而本文所获的 $\mathrm{Rb}-\mathrm{Sr}$ 同位 素等时线年龄给出了这次重要构造运动的发生时期.

\section{4 结论}

(1) 巴音高勒地区锡林郭勒杂岩的形成年龄为 $(1025 \pm 41) \mathrm{Ma}$, 等时线的 $\varepsilon_{\mathrm{Na}(T)}$ 值为 $6.25 \pm 0.73$, 表明岩浆来源于中等亏损的幔源区.

(2) 锡林郭勒杂岩的主期变质和变形年龄为 $(651 \mathrm{Ma} \pm 21) \mathrm{Ma}$, 代表华北板块北缘结束晚元 古代陆缘发育而进人古生代发展的重要地质事件.

（3）关于华北板块北缘元古代构造演化的认识, 过去一直认为白云鄂博裂谷于中元古代 $1400 \mathrm{Ma}$ 结束后, 直到早古生代才开始发育大陆边缘 ${ }^{2}$ 与 , 其间有长约 $800 \mathrm{Ma}$ 的地史空白. 而本文则从同位素年代学角度给出了另一种演化过程, 即中晚元古代 (1000 Ma左右) 华北板块 北缘仍发育被动火山陆缘, 并经历震旦纪晚期 $(650 \mathrm{Ma})$ 的强烈构造运动, 然后才开始发育早 古生代大陆边缘。

致谢 韩宝福博士帮助计算等时线的 MSWD 值并与笔者多次讨论, 在此表示感谢.

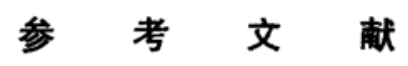

1 郡济安. 中朝板块北缘中段地壳演化. 北京: 北京大学出版社, 1991

2 唐克东, 张允平. 内蒙古琏合带的构造演化. 见: 肖序常, 汤耀庆主编. 古中亚复合巨型琏合带南缘构造演化. 北 京: 北京科学技术出版社, 1991

3 内蒙古自治区地质矿产局. 内蒙古自治区区域地质志．北京:地质出版社, 1986

4 乔广生,翟明国,阎月华。鞍山地区太古代岩石同位素地质年代学研究。地质科学, 1990, (2): 158 ～ 165

5 王 辑, 李双庆. 狼山 - 白云鄂博裂谷系及成矿特征. 见: 中国北方板块构造文集编委会. 中国北方板块构造文集, 第二集. 北京: 地质出版社, 1987. $59 \sim 72$ 